\title{
PEDOLOGIA APLICADA À CONSTRUÇÃO CIVIL NO ESTADO DO RIO GRANDE DO NORTE
}

\author{
Alexandre da Costa Pereira ${ }^{1}$ \\ Eliane Oliveira de Morais ${ }^{2}$ \\ Sandra Albino Ribeiro ${ }^{3}$ \\ ${ }^{1}$ Professor do CEFET-RN, D.Sc. alexandre@cefetrn.br \\ ${ }^{2}$ Acadêmica em Tecnologia da Produção na Construção Civil (CEFET-RN) e em \\ Administração de Empresas (UFRN). elianecefet@yahoo.com.br \\ ${ }^{3}$ Acadêmica em Tecnologia da Produção na Construção Civil (CEFET-RN) e em \\ Arquitetura e Urbanismo (UFRN). sandralbino@yahoo.com.br
}

\section{RESUMO}

O presente artigo tem como objetivo fundamental a discussão sobre a aplicação de características geomorfológicas e pedológicas de solos do Estado do Rio Grande do Norte relacionadas com comportamentos geotécnicos de interesse particular ao setor da Construção Civil. A metodologia empregada se baseia nos estudos de fatores pedológicos condicionantes de propriedades dos solos importantes para o projeto e construção de obras de engenharia civil, sendo realizada a análise dos distintos tipos pedológicos de solos e de mapas da geomorfologia e pedologia do Estado. Conclue-se que as informações baseadas nos estudos de características pedológicas dos solos podem ser úteis para a análise de macro-zonas com riscos potenciais de erosão, permeabilidade, colapsividade e expansividade de solos. Com o estudo feito, foram elaborados alguns mapas que podem ajudar no planejamento adequado do uso dos solos a fim de se evitar eventuais problemas geotécnicos.

Palavras-chave: Construção Civil, Solos, Geomorfologia e Pedologia.

\section{PEDOLOGÍA APLICADA A LA CONSTRUCCIÓN CIVIL EN LA PROVINCIA DEL RIO GRANDE DO NORTE}

\section{RESUMEN}

El presente artículo tiene como objetivo fundamental la discusión respecto la aplicación de características geomorfológicas y pedológicas de suelos de la provincia del Rio Grande do Norte relacionadas con comportamientos geotécnicos de interés particular al sector de la Construcción Civil. La metodología empleada se basa en los estudios de factores pedológicos condicionantes de propiedades de los suelos importantes para el diseño y construcción de obras de ingeniería civil, siendo realizado el análisis de los distintos tipos pedológicos de suelos y de mapas de la geomorfología y pedología de la provincia. Se concluye que las informaciones basadas en los estudios de características pedológicas de los suelos pueden ser útiles para el análisis de macro-zonas con riesgos potenciales de erosión, permeabilidad, colapsibilidad y expansibilidad de suelos.

Palabras-llave: Construcción Civil, Suelos, Pedología Aplicada. 


\section{PEDOLOGIA APLICADA À CONSTRUÇÃO CIVIL NO ESTADO DO RIO GRANDE DO NORTE.}

\section{CONSIDERAÇÕES INICIAIS}

Historicamente, no Brasil, o estudo do solo aplicado à Construção vem sendo desenvolvido a partir de 1937, quando foi montado o primeiro núcleo de pesquisa(formado no IPT, Instituto de Pesquisa Tecnológica do Estado de São Paulo). Esse estudo foi evoluindo à medida que se passou a ser útil no estudo da mineração e impacto ambientais.

Graças a esse estudo, a interação entre o homem e o solo, pode ser evitada tristes surpresas perante as obras das construções.

Várias investigações vêm sendo geradas nos últimos tempos, no intuito de relacionar a Geotécnica com áreas de conhecimentos diversos à Construção Civil, tais como a Estatística (analisa o fator de segurança), a Matemática (com o uso da moldagem numérica), e a Pedologia, além de outros.

Tratando-se da Pedologia, como ciências que visa o estudo do solo sendo um sistema em constante modificação; aliado paralelamente a fatores Geomorfológicas, a Geotécnica contribui, essencialmente, a maior quantidade e qualidade dos dados em relação à estratigrafia do solo, como também no melhoramento nos aspectos microestruturas relacionadas com as características físicas e químicas contidos nas observações pedológicas.

Para permitir uma interpretação mais adequada nos perfis pedológicos, propõe-se neste trabalho, citar os principais elementos que possam caracterizar o solo no Rio Grande do Norte. O método utilizado para desenvolver este trabalho, baseia-se na divisão dos seguintes parâmetros:
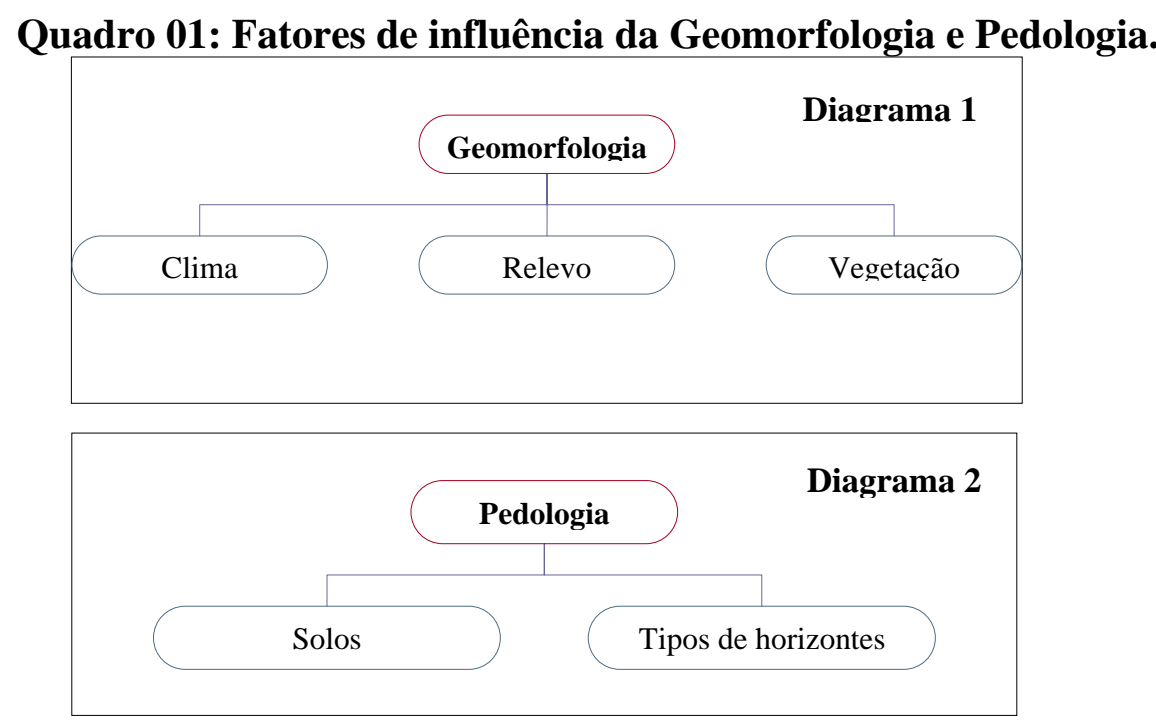


\section{GEOMORFOLOGIA DO RN}

A consulta de uma boa enciclopédia nos revela a definição do verbete "geomorfologia"[ge (o) - + morf (o) - + - logia.]: s.f. Ciência estruturada no estudo das formas do relevo terrestre.

\section{Relevo}

O relevo do Estado Potiguar apresenta características variadas, sendo representado preponderantemente por extensas superfícies planas, formadas principalmente por processos de pediplanação em litologia do cristalino e sedimentares. Interpondo-se a estas superfícies, destacam-se extensas áreas de relevo dissecadas em que os processos erosivos modelaram formas aguçadas, convexizadas e interflúviais tabulares. Estas formas geralmente caracterizam um retrabalhamento erosivo sobre as superfícies de aplainamento.

Com base numa metodologia elaborada e utilizada no Projeto RADAMBRASIL (1973; apud PEREIRA, 1995), foram identificadas cinco unidades geomorfológicas, em que se procurou explicar a evolução das mesmas. Estas foram baseadas em informações de imagens de radar que identificaram a homogeneidade de formas de relevo e semelhanças na sua gênese, são:

- Tabuleiros costeiros: Faixa contínua ao longo do litoral, com largura média de $50 \mathrm{Km}$. A altitude média varia entre 70 e $100 \mathrm{~m}$, sendo mais elevada no trecho do litoral norte até Ponta de Touros;

- Depressão sertaneja: Compreende a unidade geomorfológica de maior extensão na compartimentação do relevo, revelando caráter periférico e interplanaltico, circundando os compartimentos elevados de relevo ou se estendendo a partir das bases escarpadas dos planaltos;

- Planalto da Borborema: Esta unidade acha-se circundada em quase todos os quadrantes pela depressão Sertaneja, exceto a sudoeste onde contata com Planalto Sertanejo;

- Planaltos residuais: Destacam-se sobre a topografia plana das depressões sertanejas, constituindo-se em elevações residuais (maciços isolados). A leste da cidade de Pau dos Ferros ocorre exemplos típicos desta unidade, cuja altitude ultrapassa a cota de 600m;

- Planalto Sertanejo: Dispõe-se de forma semicircular bordejando os altos relevos do planalto da Borborema, fundamentalmente, pelo predomínio de cotas de 350m.

\section{Vegetação}

É o conjunto de plantas nativas as quais se encontram em qualquer área terrestre, desde que haja condições para o seu desenvolvimento. Considerando, mais uma vez, informações do Projeto RADAMBRASIL, esse mapeou o estado potiguar em quatro regiões ecológicas, da seguinte forma:

- A Savana: apresenta-se com as fisionomias de Savana Arbórea densa e savana Arbórea aberta, ocorrendo como disjunções nos interflúvios dos Tabulares Costeiros, a Nordeste, nas proximidades da cidade de Touros;

- Estepe: é o tipo de vegetação de maior ocorrência. Sua distribuição dá-se em torno das formas de relevo, excetuando-se as planícies fluviomarinhas e dunas não 
fossilizadas. A fisionomia Estepe Arbórea Aberta é a de maior ocorrência, embora a Estepe Arbórea Densa e a Estepe Parque sejam bastante significativos;

- As Áreas das Formações Pioneiras: são representadas por vegetação arbórea (mangue) e herbácea, distribuídas em áreas de influência fluviomarinhas e, "Restingas" arbóreas, arbustivas e herbáceas das dunas e praias. Além disso, compreende uma estreita faixa, praticamente contínua ao longo do litoral;

- As Áreas de Tensão Ecológica: caracteriza-se pela ocorrência de contatos entre diferentes tipos de vegetação. Nos tabuleiros Costeiros, as Áreas de Tensão Ecológica distribuem-se com características diferentes em função de sua localização;

- As Áreas de Tensão Antrópica: representadas por atividades agrícolas, ocorrem de maneira indiscriminadas em todas as formas de relevo, mas nos planaltos adquire maior expressividade.

\section{Clima}

O clima do Rio Grande do Norte é um fator importante no estudo pedológico, visto que é verificado nas áreas semi-áridas, predominam solos poucos espessos, tendo que as condições climáticas não favorecem o desenvolvimento do processo de edafização do material decomposto.

Diversas áreas de relevo montanhoso apresentam alterações climáticas. Desta maneira, as serras formam, às vezes verdadeiros oásis, onde a temperatura é mais agradável com médias anuais de $22{ }^{\circ} \mathrm{C}$ a $23^{\circ} \mathrm{C}$ e precipitações abundantes.

Uma das classificações climáticas mais difundidas foi proposta pelo cientista alemão Wilhelm Köppen (1846-1940), os tipos climáticos que ocorre no estado norte-riograndense são:

- As': Clima quente e úmido com estação seca no verão e chuvas no outono-inverno .Constitui uma faixa do litoral oriental da área em estudo. As temperaturas são elevadas com média anuais em torno de $24^{\circ} \mathrm{C}$;

- BSs'h': Climas muito quentes, semi-áridos, com estação chuvosa se adiantando para o outono, antes do inverno;

- BSw'h': Climas muito quentes, semi-áridos, com estação chuvosa atrasando-se para o outono. A precipitação é escassa e mal distribuída, as temperaturas nunca são inferiores a $24^{\circ} \mathrm{C}$ e a estação sua pode prolongar-se até dez meses. Ocorre em maior proporção em relação aos outros tipos de climas;

- Aw': Clima tropical chuvoso, quente e úmido, com chuvas de verão e precipitação máximas no outono. Apresenta-se em pequenas áreas do Estado.

As Figuras 1 e 2 nos mostra, respectivamente, as características da vegetação e clima do Estado do RN. 


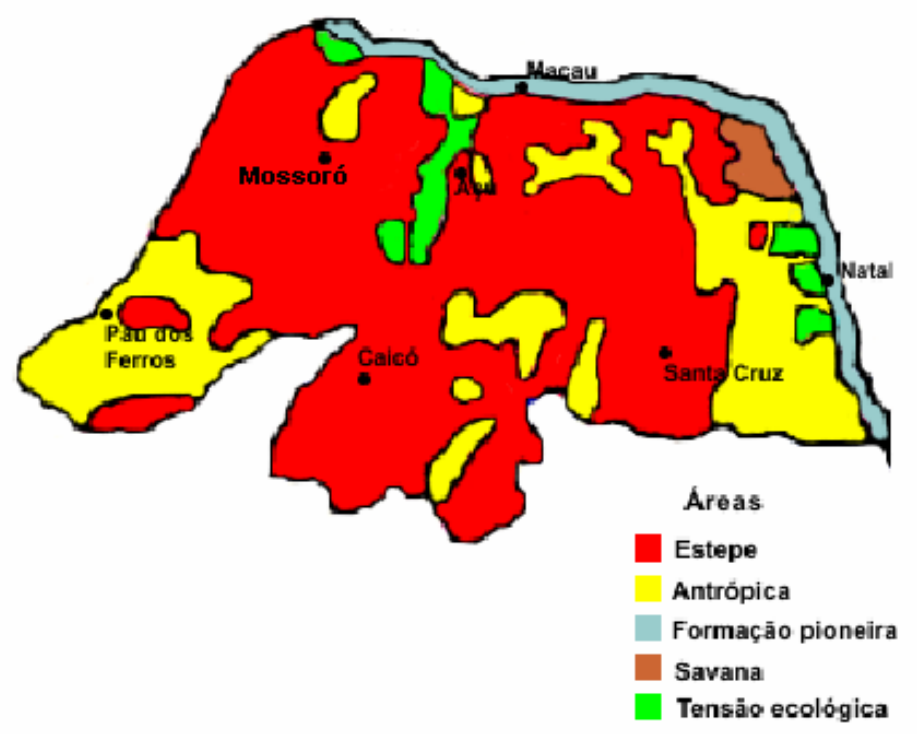

Figura 1- Mapeamento da vegetação do Estado do RN.

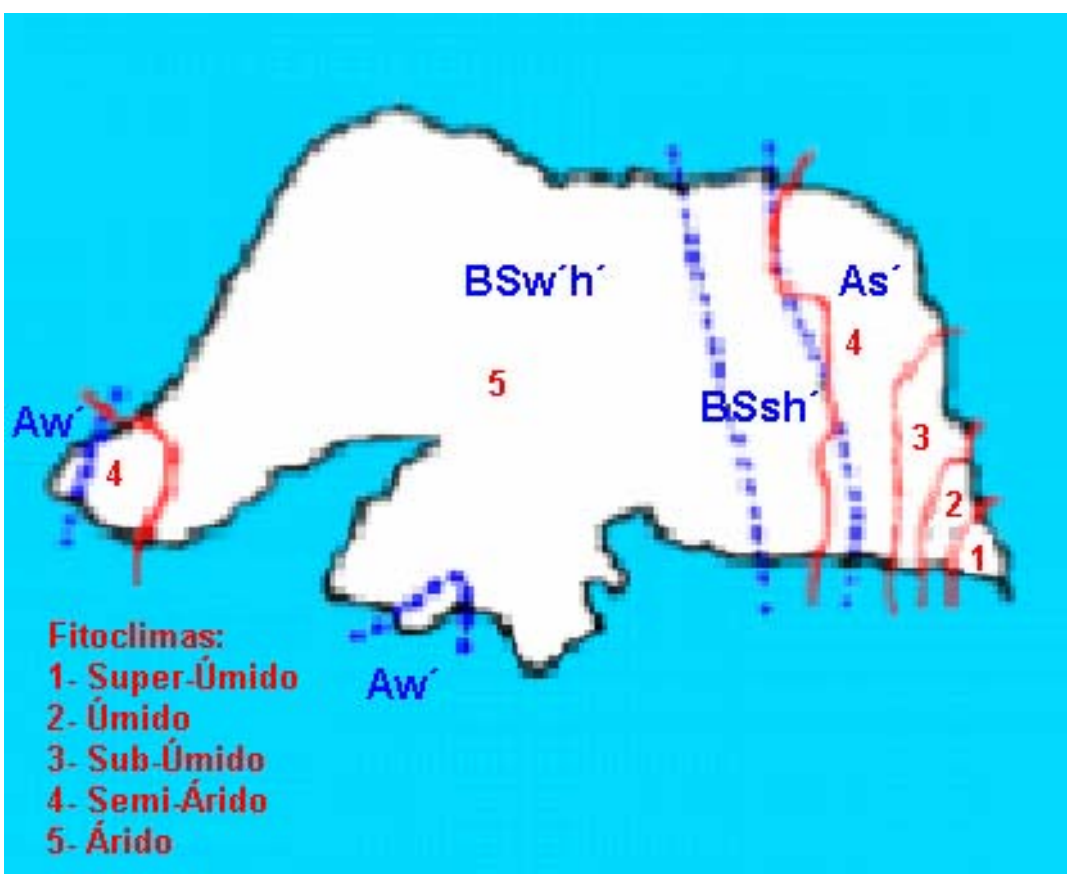

Figura 2- Mapeamento climático do Estado do RN (classificação segundo Köppen).

\section{SOLOS}

Para analisar os diversos tipos de solo do estado potiguar, usaremos o ramo da Geografia Física (responsável pela constatação dos tipos de solo), conhecida como Pedologia.

Conceitualmente, o solo é o conjunto de horizontes ou camadas que se deu pela desintegração da rocha-mãe. Paralelamente a isso, esse fenômeno sofre influências físicas e químicas.As propriedades físicas do solo são elementos importantes, pois os solos diferenciam-se quanto à:

- Textura: é caracterizado pelo o tamanho das partículas, enfim na capacidade de infiltração e de absorção da água; 
- Estrutura: é o modo como se arranjam às partículas de solos, igualmente à textura, influi na capacidade de infiltração e absorção da água;

- Permeabilidade: determina a maior ou menor capacidade de infiltração que estão diretamente relacionados com a porosidade;

- Densidade do Solo: é inversamente proporcionais a porosidade e permeabilidade por efeito de compactação do solo, logo se torna mais erodível;

- Matéria Orgânica: é incorporada no solo permitindo uma maior agregação e coesão entre partículas tornando o solo mais estável em presença de água, mais poroso e com maior poder de retenção de água.

\section{Tipos de Horizontes}

\section{Horizonte B Latossólico}

O tipo de solo latossólico predominante, em nosso Estado, é o latossolo vermelho-amarelo.

- Latossolo vermelho-amarelo: São solos não hidromórficos desenvolvidos em zonas de oxidação, em ótimas condições de drenagem, nunca afetado por lençol freático, além disso, são solos muito profundos, freáticos, porosos, muito permeáveis, aparentemente sem estrutura, de excelentes qualidades físicas e de notável resistência à erosão, possuem uma boa capacidade de armazenamento de água.

Os latossólico apresentam pouca diferença entre o horizonte A e B. Sendo o horizonte A geotecnicamente desprezível pela reduzida espessura em relação ao horizonte $\mathrm{B}$, o qual é um solo mais maduro e pode representar importante fonte de argilas para aterros ou núcleo de barragens (FERREIRA, 1993).

\section{Horizonte B Textural}

Apresenta-se como horizonte mineral iluvial com concentração de argila translaçada do horizonte A. Além disso, há uma diferença textural entre os horizontes $\mathrm{A}$ e $\mathrm{B}$, sendo o horizonte A de textura menos argilosos e mais facilmente erodidos. O horizonte B é iluvial, normalmente evidenciado pela presença de cerosidade. No Rio Grande do Norte os tipos desses solos são.

- Bruno não Cálcico: são solos próprios de regiões semi-áridas quentes, sendo argila de atividade bem alta e eutrófico. Além disso, apresentam problemas ligados à erosão e por vezes perigos de salinização. Têm, geralmente, descontinuidade litológica entre os horizontes superficiais e subsuperficiais, tendo mudança textural abrupta do horizonte A para o horizonte B;

- Podzólico Vermelho Amarelo: são solos com argilas de atividade baixas ou altas, rasas ou profundas, com drenagem e aeração, normalmente não apresenta problemas. São poucas resistentes as erosões. A diferença desse solo para o latossolos consiste principalmente no gradiente textural entre os horizontes A e B, uma vez que o podzólico contém horizonte B textural, caracterizando um horizonte mais arenoso que o horizonte $\mathrm{B}$. Contém horizontes $\mathrm{A}$ mais arenosa que o horizonte $\mathrm{B}$, que se assemelha ao latossolo, com comportamento laterítico;

- Podzólico Vermelho Amarelo Eutrófico: Apresenta argila de atividade baixa ou alta, horizonte A fraco, textura arenoso/média com drenagem moderada. Os solos Podzólicos apresentam-se como classe pedológica que apresentou maior potencial de colapso. Assemelha-se aos Latossolos colapsível de textura média em termos de 
caracterização e índices físicos. Quanto à expansibilidade, teremos também a sua presença em função de uma série de fatores intrínsecos ao próprio solo e outras condicionadas ao meio ambiente em que se encontram (saturação, cimentação, tensão).

- Planossolo Solódico: são solos que possuem, normalmente, argila de atividade alta, sendo moderadamente profundas e rasas, sendo a transição do horizonte A para o B, normalmente abrupta. São solos muito susceptíveis à erosão e apresentando sódio em valores mais altos faz com que os teores de argila natural sejam mais significantes nestes solos e nessa condição resultam solos de baixa permeabilidade associados com umidade.

\section{Horizonte B Solonétzico}

Solonetz-Solodizado: são solos com seqüência A, B e C bem diferenciados entre si, com mudança textural abrupta do A para o B. São rasos a medianamente profundos. Os altos teores de sódio trocável desses solos fazem com que grande parte da fração argila esteja dispersa na massa do solo, resultando numa permeabilidade lenta e, conseqüentemente, más condições de drenagem (FERREIRA, 1995).

\section{Horizonte B Câmbico}

Cambissolo Eutrófico: são solos não hidromórficos, medianamente profundos a rasos. A porosidade e a boa permeabilidade dos Cambissolos fazem com que eles sejam moderadamente drenados.

\section{Horizonte Glei}

São solos de sedimentos argilosos que apresentam perfil com seqüência A e C. Além de apresentarem horizonte superficial, é rico em matéria orgânica e subsuperficial de cor cinzenta geralmente mosqueada devido aos fenômenos de oxi-redução. Além disso, apresenta perfil com a seqüência $\mathrm{A}$ e $\mathrm{C}$, estando o lençol d'água presente muito próximo à superfície, havendo má drenagem e acúmulo de matéria orgânica.

- Solos Glei: ocorrem em área muito baixas, têm relevo plano, geralmente nas proporções terminais de alguns rios. Compreendem solos Glei Húmico e pouco Húmico, diferenciando-se pela espessura do horizonte A e por sua cor.

\section{Horizonte Sálico}

São solos com excesso de sais. As suas condições de drenagem ocasionam o aparecimento, nas camadas subjacentes ao horizonte superficial, mosqueados e/ou cores de redução proveniente da gleização. Quando originados de deposições recentes, os solos aqui caracterizados assemelharam-se aos solos aluviais, tendo na salinidade a principal diferenciação.

- Solonchak solonético: apresentam elevados teores de sódio trocável, possuindo, horizonte A pouco espesso. Em épocas secas, observam-se crostas de sais cristalinos nas superfícies das áreas onde ocorrem esses solos.

- Solos indiscriminados de mangues: ocorrem no litoral, geralmente próximo às desembocaduras dos rios apresentando uma vegetação característica denominada de manguezais. São solos não ou muito pouco desenvolvidos, mal drenados, com alto 
conteúdo de sais proveniente da água do mar e decomposto de enxofre, ocorrendo matéria orgânica, proveniente da decomposição das plantas de mangues.

\section{Solos sem Horizonte B (ou pouco desenvolvido)}

São solos não hidromórficos e pouco evoluídos, seja pela grande resistência ao intemperismo do seu material originário, seja pelo fato de que a expansão do seu material original ainda não tenha sido bastante longa para provocar evolução mais avançada (MARIZ, 1973).

- Areia Quartzosa Distrófica: são solos essencialmente quartzosos, de textura arenosa com menos de $15 \%$ de argila, com espessura variada. Apresentam seqüência de horizonte $\mathrm{A}$ e $\mathrm{C}$, ocorrendo em grandes extensões, principalmente na zona do litoral, relacionados com as classes de relevo plano e suave ondulado. As essas areias podem apresentar comportamento colapsível, (principalmente quando a porcentagem de areia > 50\%) ou expansivos.

- Solos Aluviais Eutrópicos: classe integrada com solos pouco desenvolvido, apresentando horizonte A fraco, moderado ou chernozênico sobrejacente a camadas estratificadas. Ocorrem em vários rios, relacionados a relevo plano.As camadas subjacentes ao horizonte A não guardam pedogenéticas entre si, variam em sua composição e granulometria e não tem disposição preferencialmente. Nos solos argilosos imperfeitamente drenados, é comum a presença de mosqueados. Nas áreas onde há algum acúmulo de água no período chuvoso, há indícios de gleização podendo ser verificados nas camadas inferiores. Podem ser colapsíveis ou expansivos, de forma semelhante às Areias Quartzosas.

- Vertissolo: os solos dessa classe são minerais, não hidromórficos, argilosos a muito argilosos, tendo em sua composição alto conteúdo de argila e quando secos nota-se nestes solos, na estação chuvosa tornam-se bastante susceptível à erosão.

- Rendzinas: os solos dessa classe são derivados de calcário, possuem horizonte A chernozênico bem desenvolvido, são relativamente rasos e moderados a imperfeitamente drenados.

- Solos Litólicos Eutróficos: Compreende solos pouco desenvolvidos, em que a rocha consolidada pouco ou sem nenhuma meteorização, encontra-se a profundidade não superior a $0,50 \mathrm{~m}$. Como também solos que não apresentam rochas consolidadas próximas à superfície, porém a quantidade de cascalhos, matações, pouco ou nada decompostos é consideravelmente elevada.

- Regossolos Eutróficos: classe de solos normalmente arenosos, pouco desenvolvidos, não hidromórficos, com horizontes na seqüência A e C, podendo ou não apresentar fragipan logo acima da rocha. São profundos a moderadamente profundos, porosos, moderada a excessivamente drenados. A textura arenosa cascalhenta foi verificada em alguns solos dessa classe, como também a susceptibilidade à erosão.

\section{ANÁLISE DAS INFORMAÇÕES}

Baseando-se nas características geotécnicas consideradas para as distintas classes pedológicas dos solo, poderíamos utilizar-nos de mapas pedológicos para a obtenção de mapas de riscos geotécnico potenciais, fundamentalmente relacionados com 0 comportamento frente à erodibilidade e permeabilidade, expansibilidade e colapsividade dos solos do Estado Potiguar. 


\section{Sobre a Erodibilidade e Permeabilidade dos Solos:}

Considerando o mapeamento pedológico apresentado no item anterior, temos o predomínio na parte litoral uma erodibilidade baixa enquanto que sua permeabilidade é potencialmente alta. Já na parte sul do Estado tem o prevalecimento de uma erodibilidade alta e permeabilidade baixa, como podemos verificar nas Figuras 3 e 4, logo abaixo (PEREIRA, 1995).

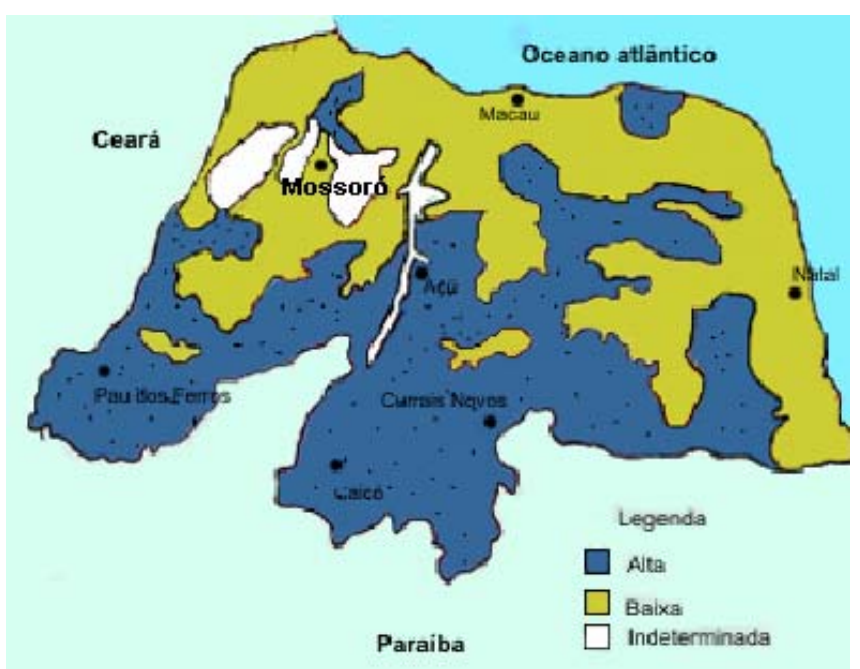

Figura 3- Mapa de risco potencial de erodibilidade.

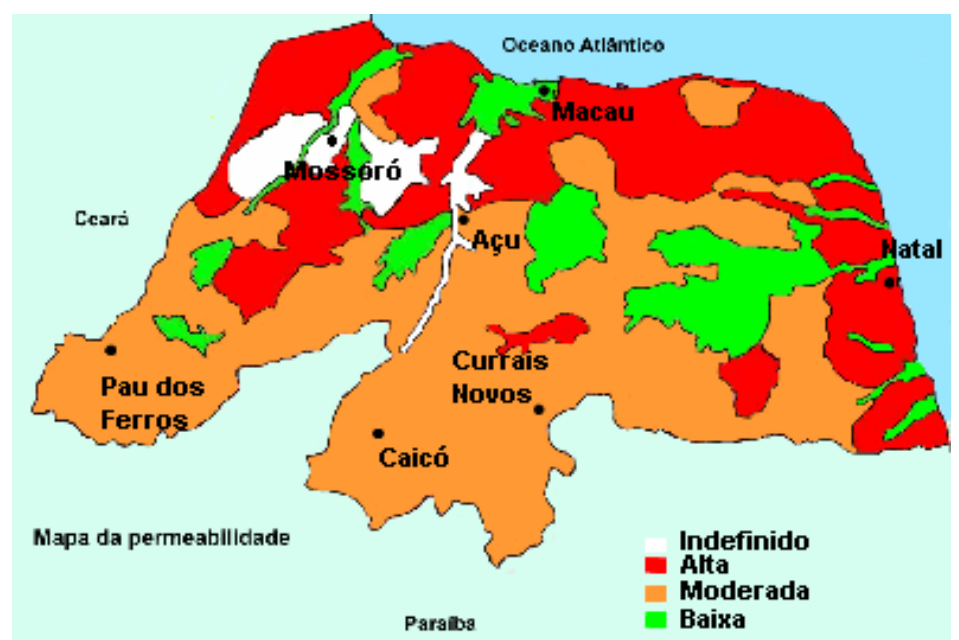

Figura 4- Mapa de permeabilidade potencial dos solos.

\section{Sobre a Expansividade e Colapsividade dos Solos}

Segundo PEREIRA (1995), na maior parte do Oeste Potiguar, tem-se a presença de uma área de menor risco de expansibilidade e a maior parte do Estado existe uma maior presença de solos potencialmente colapsíveis, como podemos visualizar nas Figuras 5 e 6. 


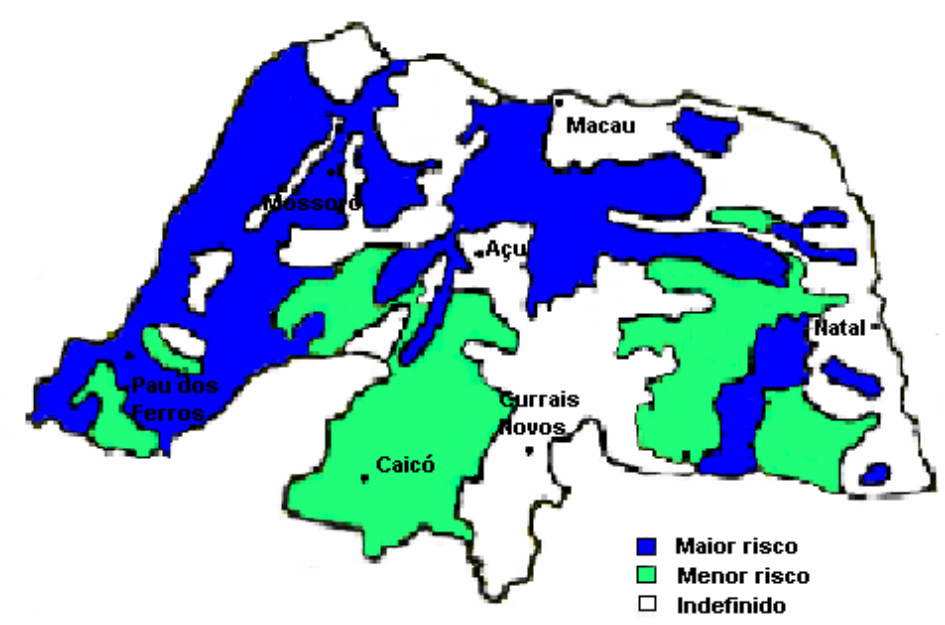

Figura 5- Mapa de risco potencial de expansividade.

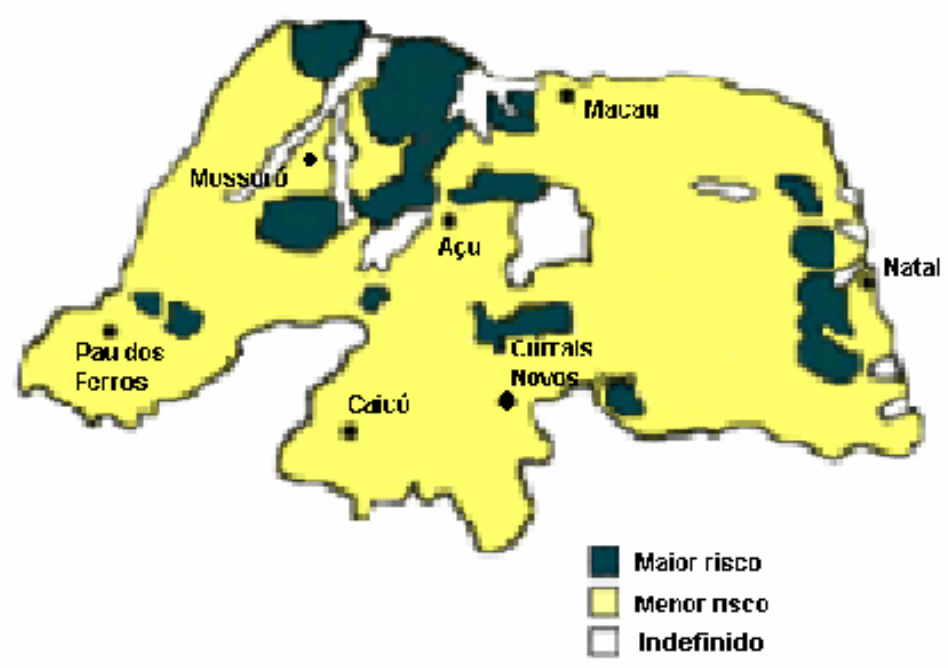

Figura 6- Mapa de risco potencial de colapsividade.

\section{CONSIDERAÇÕES FINAIS}

A análise da caracterização geotécnica com o uso de diversos mapas de solos, associados aos fatores geomorfológicos podem nos esclarecer sobre o comportamento do solo a favor da construção civil. É importante enfatizar que numa mesma classe pedológica o comportamento do solo pode variar de acordo com os fatores geomorfológicos, a exemplo do clima. Sabendo que a Pedologia é utilizada para fins agrícolas, convém destacar que a mesma pode vir a nos esclarcer diversos pontos que souscitam dúvidas quando tratamos, principalmente, de grandes obras de engenharia (estradas, barragens, canais,...).

É importante ressaltar, ainda, que a variabilidade no comportamento dos solos pode se apresentar de forma importante dentro de uma mesma classe pedológica. O clima, neste 
enfoque, é o fator geomorfológico mais importante, podendo atuar, por exemplo, como elemento decisivo na colapsividade efetiva de um solo.

\section{REFERÊNCIAS BIBLIOGRÁFICAS}

ALHEIROS, M. M e LIMA FILHO, M. F. (1991). A Formação Barreiras. In: Estudos e Pesquisas, Depto. Geologia, UFPE, pp. 77-88.

IDEC (1978). Mapa Pedológico do RN.

FERREIRA, S. R. M. (1995). Características dos Principais Horizontes Diagnósticos das Classes Pedológicas. Relatório FACEPE, Recife.

FERREIRA, S. R. M. (1993). Aplicações da Classificação e Levantamentos Pedológicos aos Estudos dos Solos Colapsíveis e Expansivos. Revista Ciência e Engenharia, UFU, No 01, Ano 02, pp. 119-136.

MARIZ, A. C. (1973). Elementos de Pedologia. Ed. USP, São Paulo.

PEREIRA, A. C. (1995). Geomorfologia e Pedologia do Estado do Rio Grande do Norte. UFPE, Curso de Mestrado em Geotecnia (Seminário), Recife.

PRANDINI, F. L. et al. (1994). Cartografia Geotécnica nos Planos Diretores Regionais e Municipais. In: $5^{\circ}$ Curso de Geologia Aplicada ao Meio Ambiente, São Paulo, pp. 233-246.

http: // www.sbo.oceanografia.org/trabalho/ver/348.txt. Acesso em 15 de Ago. 2004, 19:45:25.

SANTORO, J. (1995). A Geologia de Planejamento e o Meio Ambiente. Secretaria do Meio Ambiente, Coord. de Informações Técnicas, Documentação e Pesquisa Ambiental: Instituto Geológico, São Paulo.

\section{ANEXO}

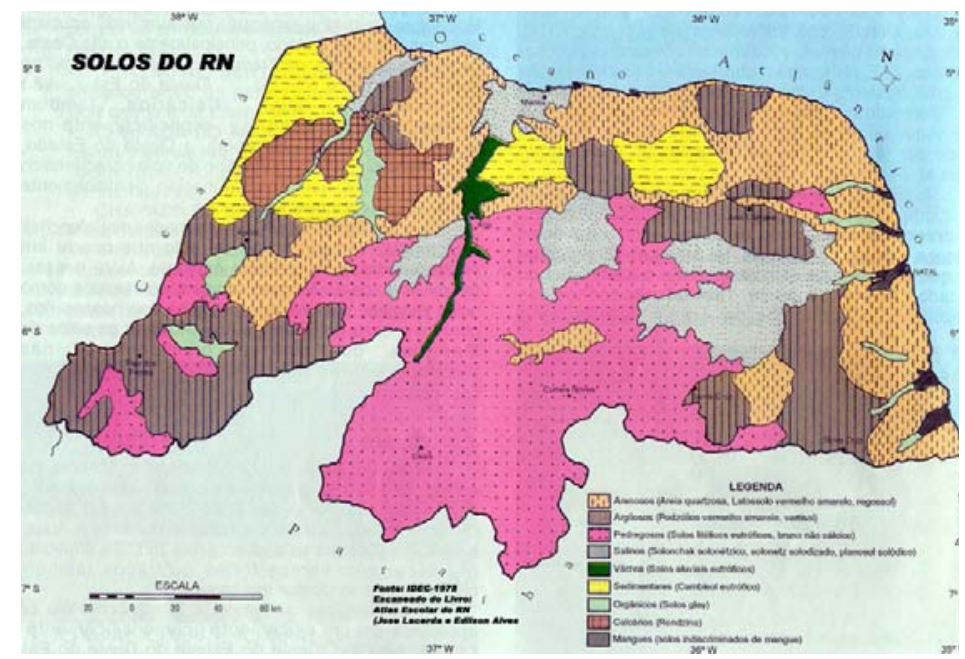

Mapa Pedológico do RN (IDEC, 1978; apud PEREIRA, 1995) 